\title{
PROSES PRODUKSI ALMOND CRISPY UBI JALAR
}

\section{Sandy Tri Wibowo, Bara Yudhistira, Nur Her Riyadi Parnanto}

Fakultas Pertanian Universitas Sebelas Maret, Jl. Ir. Sutami No.36A, Surakarta, 57126, Indonesia.

Email: sandyhaw20@gmail.com

\begin{abstract}
ABSTRAK
Almond Crispy Ubi Jalar merupakan makanan inovasi yang tergolong kedalam produk cookies/kue kering. Pengolahan Almond Crispy sendiri dilakukan dengan penambahan ubi jalar ungu dan ubi jalar kuning yang telah melalui proses penepungan dalam memberikan hal baru terhadap cita rasa dan kandungan dari produk Almond Crispy. Proses pembuatan Almond Crispy Ubi Jalar meliputi proses pencampuran/mixing, penambahan bahan kering, pencetakan adonan, pengovenan/pemanggangan, pendinginan dan pengemasan. Pengujian sensoris Uji Kesukaan dilakukan untuk mengetahui tingkat kesukaan dan daya terima konsumen. Sampel terpilih dalam pengujian sensoris meliputi, sampel Almond Crispy penambahan Ubi Ungu pada sampel F3 $(50 \%=75$ gram $)$ dan sampel Almond Crispy penambahan Ubi Kuning pada sampel F1 $(30 \%=45$ gram). Untuk mengetahui karakteristik produk akhir dilakukan pengujian Aktivitas Antioksidan pada sampel Ubi Ungu (16,45\%) dan sampel Ubi Kuning $(11,83 \%)$ serta pengujian Total Kalori pada sampel Ubi Ungu $(4,940 \mathrm{kkal} / \mathrm{g})$ dan sampel Ubi Kuning $(5,190 \mathrm{kkal} / \mathrm{g})$. Berdasarkan perhitungan Analisis Ekonomi yang dilakukan mengenai penentuan HPP, BEP, ROI, POT, NPV dan IRR maka usaha produksi Almond Crispy Ubi Jalar ini menguntungkan dan layak untuk dijalankan.
\end{abstract}

Kata kunci: proses produksi, cookies, almond crispy, ubi jalar

\section{ABSTRACT}

Almond Crispy of sweet potato was inovation of food that included into the cookies product. The processing of Almond Crispy itself carried out with adding of violet sweet potato and yellow sweet potato already through powdering to give new taste towards flavor and content of Almond Crispy product. The process of manufacturing Almond Crispy of sweet potato included the mixing process, the adding of arid ingredient, the casting of dough, the roasting, the colling and the last packaging. The testing of delight sensory carried out to know the level of delight and the potency of consumer accepting. The sample that chosen on sensory testing included the sample of Almond Crispy adding to violet sweet potato, the sample was $F 3(50 \%=75$ gramme $)$ and the sample of Almond Crispy adding to yellow sweet potato, the sample was F1 $(30 \%=45$ gramme $)$. To determine the characteristic of the last product did the testing of antioxidant activity and the sample of violet sweet potato there was $(16,45 \%)$ and the sample of yellow sweet potato there was $(11,83 \%)$, along with the testing of total calorie 
on violet sweet potato sample that was $(4,940 \mathrm{kkal} / \mathrm{g})$ and yellow sweet potato sample that was $(5,190 \mathrm{kkal} / \mathrm{g})$. Based on the calculation of economy analysis that did determining concern of HPP, BEP, ROI, POT, NPV and IRR so this effort of Almond Crispy Sweet Potato production can profitable and suitable for operation.

Key words: production process, cookies, almond crispy, sweet potato

\section{PENDAHULUAN}

Tanaman ubi jalar di Indonesia memiliki potensi yang cukup baik, akan tetapi pemanfaatannya sendiri masih terbatas. Pemanfaatan ubi jalar sendiri dapat dijadikan bahan baku industri jika dipertimbangkan dari fleksibilitas bahan pangan dan kandungan gizinya. Dari beberapa jenis ubi jalar yang tersebar di Indonesia, yang cukup banyak dimanfaatkan yaitu ubi jalar ungu dan ubi jalar kuning. Selain karena pigmen antosianin yang dimiliki ubi ungu dan karotenoid yang dimiliki ubi kuning, masih banyak kandungan yang dimiliki ubi jalar ungu dan ubi jalar kuning yang bermanfaat untuk tubuh manusia.

Salah satu pengolahan ubi jalar yang paling sederhana adalah dijadikan tepung. Tepung dari ubi jalar dapat dimanfaatkan menjadi bahan baku dan bahan substitusi terigu pada industri makanan olahan. Proses praktik produksi ini bertujuan agar dapat menjadi upaya mengurangi ketergantungan terhadap tepung terigu. Selain itu, proses pembuatan produk ini dilakukan guna menciptakan inovasi produk Almond Crispy sendiri serta dapat meningkatkan olahan ubi jalar menjadi pangan yang fungsional, memberikan inovasi dalam pengolahan Almond Crispy yang menjadi makanan sehat, kaya akan serat dengan penambahan ubi jalar, menjadikan alternatif pilihan makanan sehat, enak, bergizi dan kaya energi dalam pemenuhan kalori. Tujuan dari penelitian ini yaitu: 1) Mengetahui proses pembuatan Almond Crispy Ubi Jalar. 2) Mengetahui kandungan antioksidan dan total kalori pada Almond Crispy Ubi Jalar. 3) Mengetahui formulasi Almond Crispy Ubi Jalar yang disukai panelis. 4) Melakukan analisa kriteria kelayakan usaha untuk produk Almond Crispy Ubi Jalar.

\section{METODE}

Untuk mencapai tujuan yang diharapkan maka penelitian yang akan dilaksanakan adalah sebagai berikut:

Melakukan Proses Praktik Produksi Almond Crispy Ubi Jalar Praktek Proses Produksi "Almond Crispy Ubi Jalar" dilaksanakan pada bulan Januari 2018 sampai dengan bulan Juni 2018. Bahan-bahan yang digunakan dalam proses pembuatan Almond Crispy Ubi Jalar meliputi, tepung ubi jalar ungu, tepung ubi jalar kuning, tepung terigu, mentega/margarin, gula, putih telur, keju, baking powder, kacang almond. Bahan yang digunakan dalam pembuatan Almond Crispy Ubi Jalar didapatkan dari Toko Bahan Kue daerah Pasar Gede. Tahapan proses pembuatan Almond Crispy Ubi Jalar dapat dilihat pada Gambar 1. 
a. Melakukan Analisis Sensori untuk mengetahui tingkat kesukaan panelis terhadap produk yang diteliti

Analisis sensori yang dilakukan menggunakan Uji Kesukaan. Dimana kegiatan pengujian organoleptik melibatkan sebanyak 30 panelis semi terlatih. Menurut Susiwi (2009) dalam Tarwendah (2017), bahwa Uji hedonik merupakan pengujian yang dilakukan dengan prinsip panelis memberikan tanggapan pribadinya tentang kesukaan atau ketidaksukaannya terhadap suatu komoditi. Analisis sensori dinilai berdasarkan kesukaan konsumen terhadap parameter rasa, aroma, warna, tekstur dan overall. Pemilihan formulasi dipertimbangkan berdasarkan proses percobaan praktik produksi yang telah dilakukan. Sehingga dipilih formulasi pada taraf penambahan sebesar 30\% $=45$ gram, $40 \%=60$ gram, dan $50 \%=75$ gram dari $100 \%$ tepung terigu $=150$ gram

\section{b. Melakukan Analisis Kimia untuk mengetahui kandungan dalam produk yang diteliti}

Analisis Kimia yang diujikan meliputi uji Aktivitas Antioksidan dengan metode DPPH free radikal scavenger menggunakan alat spektroskopi UV-Vis dan uji Total Kalori menggunakan alat yang bernama bomb calorimeter. Analisis Kimia diujikan pada sampel terpilih pada Analisis Sensoris. Pengujian dilakukan di Laboratorium Fakultas Teknologi Pertanian UGM Yogyakarta.

\section{c. Melakukan Analisis Ekonomi untuk menentukan kelayakan usaha pada produk yang diteliti.}

Analisis ekonomi merupakan perhitungan yang menitikberatkan keuangan selama usaha dijalankan. Tujuan dari analisis ekonomi adalah untuk menentukan perhitungan biaya produksi, harga pokok penjualan, perkiraan rugi atau laba dan kriteria kelayakan (Astawan, 2004). Analisis yang dilakukan dalam penentuan kelayakan ekonomi meliputi: HPP, BEP, ROI, POT, NPV dan IRR. 


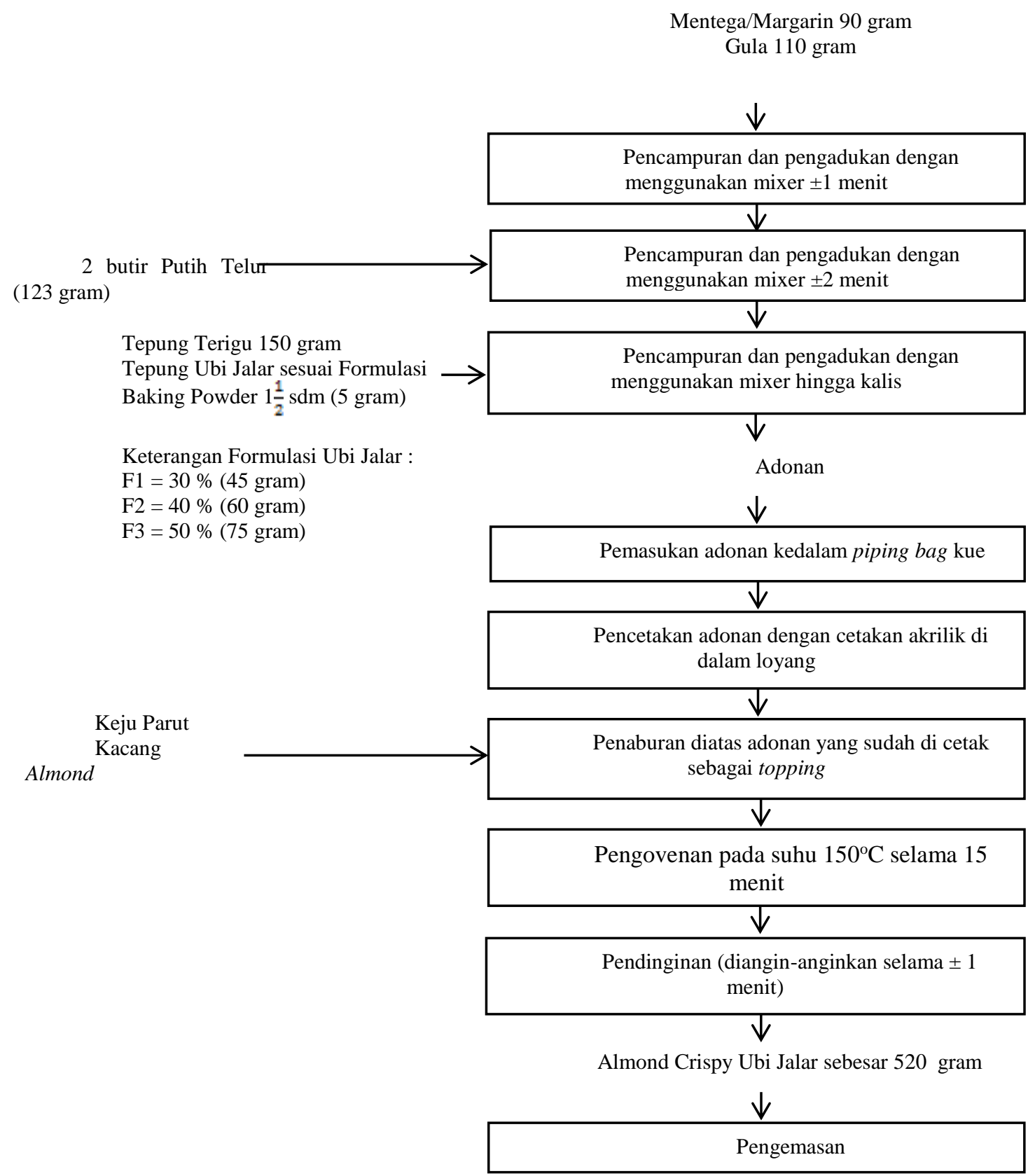

Gambar 1 Diagram Alir Pembuatan Almond Crispy Ubi Jalar (Anonim, 2017)

\section{HASIL DAN PEMBAHASAN}

\subsection{Melakukan Proses Praktik Produksi Almond Crispy Ubi \\ Jalar}

Produk Almond Crispy di Indonesia selama ini dikenal sebagai produk khas yang berasal dari Surabaya Jawa Timur. Melihat cukup banyak minat masyarakat maka muncul sebuah gagasan untuk memberikan inovasi terhadap produk Almond Crispy dengan menambahkan ubi jalar dalam peningkatan dan pemanfaatan pangan lokal yang fungsional. Almond Crispy Ubi Jalar merupakan makanan inovasi yang tergolong 
kedalam produk cookies/kue kering. Pengolahan Almond Crispy sendiri dilakukan dengan penambahan Ubi Jalar dalam memberikan hal baru terhadap cita rasa dan kenampakan dari produk Almond Crispy. Ubi jalar yang digunakan dalam proses produksi ini adalah ubi jalar ungu dan ubi jalar kuning yang telah melalui proses penepungan. Tekstur yang tipis membuat produk Almond Crispy ini memiliki kerenyahan disetiap gigitannya. Produk ini memiliki kelebihan selain cita rasa yang menarik dan kandungan gizi yang baik, juga memiliki daya simpan yang lama.

Dalam pembuatannya, produk Almond Crispy menggunakan bahan baku tepung terigu, tepung ubi jalar ungu dan kuning (yang diproses secara terpisah), gula, telur, dan margarin. Serta bahan tambahan yang digunakan dalam proses pembuatan Almond Crispy Ubi Jalar adalah baking powder, keju dan kacang almond yang telah dislicing sebagai topping. Proses produksi Almond Crispy Ubi Jalar dapat dijelaskan dengan beberapa tahapan sebagai berikut:

Tahap Pencampuran/ Mixing

Pencampuran atau mixing diawal proses yaitu dengan mengocok margarin dan gula terlebih dahulu hingga halus \pm 1 menit dengan kecepatan mixer yang cukup tinggi. Kemudian tambahkan putih telur yang sudah dipisahkan dengan kuningnya lalu dimixer kembali hingga adonan merata \pm 2 menit.

\section{Tahap Pencampuran Bahan Kering \\ Pencampuran bahan kering} pada pembuatan Almond Crispy Ubi Jalar ini meliputi tepung terigu, tepung ubi jalar dan baking powder yang sebelumnya sudah dicampur menjadi satu didalam satu wadah dan dicampur menggunakan mixer dengan kecepatan tinggi \pm 1 menit kemudian kecepatan sedang hingga tercampur rata. Tujuan pencampuran bahan kering dilakukan secara terpisah terlebih dahulu agar bahan kering mendapatkan kondisi yang merata, sehingga saat pengadukan dilakukan, adonan akan lebih merata dan tidak terjadi penumpukan atau penggumpalan adonan.

\section{Tahap Pembentukan Adonan}

Pembentukan adonan dilakukan dengan mengoleskan sedikit adonan pada setiap lubang cetakan yang telah dilapisi kertas roti. Adonan diratakan menggunakan sendok hingga berbentuk bulatan tipis. Kemudian taburkan kacang almond dan parutan keju sebagai topping.

Tabel 1. Hasil Uji Sensori "Almond Crispy Ubi Jalar (Ubi Ungu)"

\begin{tabular}{|c|c|c|c|c|c|}
\hline \multirow{2}{*}{$\begin{array}{ll}1 . & \text { Kode } \\
\text { Sampel }\end{array}$} & \multicolumn{5}{|c|}{ 2. Parameter } \\
\hline & 3. Warna & 4. Aroma & 5. Rasa & 6. Tekstur & 7. Overall \\
\hline 8. 898 & 9. $3,10^{a}$ & 10. $2,97 \mathrm{a}$ & 11. $3,43^{a}$ & 12. $3,70^{a}$ & 13. $3,37^{a}$ \\
\hline 14. 755 & 15. $3,20^{\mathrm{ab}}$ & 16. $3,07 a$ & 17. $3,63^{a}$ & 18. $3,70^{\mathrm{a}}$ & 19. $3,60^{\mathrm{a}}$ \\
\hline 20. 313 & 21. $3,67^{b}$ & 22. $3,37 \mathrm{a}$ & 23. $3,73^{a}$ & 24. $3,73^{a}$ & 25. $3,80^{a}$ \\
\hline
\end{tabular}


Tabel 2. Hasil Uji Sensori "Almond Crispy Ubi Jalar (Ubi Kuning)"

\begin{tabular}{cccccc}
\hline 26. Kode & \multicolumn{5}{c}{ 27. Parameter } \\
\cline { 2 - 6 } Sampel & 28. Warna & 29. Aroma & 30. Rasa & 31. Tekstur & 32. Overall \\
\hline 33. 898 & $34.2,67^{\mathrm{a}}$ & $35.3,00^{\mathrm{a}}$ & $36.3,03^{\mathrm{a}}$ & $37.3,47^{\mathrm{a}}$ & $38.2,97^{\mathrm{a}}$ \\
39. 311 & $40.3,97^{\mathrm{b}}$ & $41.3,60^{\mathrm{b}}$ & $42.3,77^{\mathrm{b}}$ & $43.3,77^{\mathrm{a}}$ & $44.3,90^{\mathrm{b}}$ \\
45. 755 & $46.3,97^{\mathrm{b}}$ & $47.3,77^{\mathrm{b}}$ & $48.3,87^{\mathrm{b}}$ & $49.3,90^{\mathrm{a}}$ & $50.3,97^{\mathrm{b}}$ \\
\hline
\end{tabular}

Tabel 3. Hasil Analisis Kimia Kandungan Aktivitas Antioksidan dari Almond Crispy Ubi Jalar.

51. Sampel

52. Aktivitas Antioksidan DPPH (\%)

Ubi Jalar Ungu (F3 = $50 \%)$

54. 16,45

Ubi Jalar Kuning (F1 = $30 \%)$

56. 11,83

Tabel 4. Hasil Analisis Kimia Kandungan Total Kalori didalam Almond Crispy Ubi Jalar sesuai Formula yang terpilih.

\begin{tabular}{cc}
\hline 57. $\quad$ Sampel & 58. Total Kalori (kal/g) \\
\hline Ubi Jalar Ungu (F3=50\%) & 60.494 \\
Ubi Jalar Kuning (F1 = 30\%) & 62.519
\end{tabular}

\section{Tahap Pengovenan}

Adonan yang telah dicetak kemudian dilakukan proses pengovenan dengan waktu pengovenan \pm 15 menit pada suhu $\pm 150^{\circ} \mathrm{C}$.

\section{Tahap Pendinginan}

Proses pendinginan dilakukan dengan cara angin-anginkan $<1$ menit. agar saat Almond Crispy Ubi Jalar dikemas tidak menguap saat didalam kemasan. Produk Almond Crispy Ubi Jalar yang sudah agak dingin dilakukan proses penimbangan untuk dilakukan proses pengemasan.

\subsection{Melakukan Analisis Sensori untuk mengetahui tingkat kesukaan panelis terhadap produk yang diteliti}

Dalam praktik proses produksi "Almond Crispy Ubi Jalar" dilakukan pengujian sensoris produk menggunakan sebanyak 30 orang panelis semi terlatih. Pengujian sensoris yang dilakukan yaitu menggunakan Uji Kesukaan. Produk Almond Crispy Ubi Jalar yang diuji organoleptik terdiri dari 3 formulasi yang di tambahkan tepung ubi jalar ungu dan tepung ubi jalar kuning sesuai formulasi penambahan tepung masing masing jenis ubi jalar yaitu sebesar $(30 \%=45$ gram, $40 \%=60$ gram dan $50 \%=75$ gram). Parameter dari uji hedonik Almond Crispy Ubi Jalar meliputi warna, aroma, rasa, tekstur, dan overall. Formulasi yang terpilih adalah sampel yang paling banyak dipilih oleh panelis berdasarkan parameter overall. Skala yang digunakan dari parameter tersebut adalah 1 (sangat tidak suka), 2 (tidak suka), 3 (netral), 4 (suka) dan 5 (sangat suka). Pengujian dilakukan dengan taraf signifikansi sebesar 0,05 dan tingkat keakuratan sebesar $95 \%$.

Penetapan formulasi terpilih berdasarkan keseluruhan (overall) tingkat kesukaan panelis terhadap semua parameter. Formulasi terpilih yaitu sampel kode 313 dengan formulasi penambahan tepung ubi jalar ungu sebesar 75 gram. Secara 
statistika dari ketiga sampel tidak berbeda nyata, namun dari perolehan skor angka, maka dipilih sampel 313 (penambahan tepung ubi jalar ungu sebesar 75 gram) yang paling disukai oleh panelis.

Selain itu pertimbangan yang dilakukan dalam pemilihan formulasi 313 dengan penambahan tepung ubi jalar ungu sebesar 75 gram dilihat dari segi kualitas produk yang dihasilkan. Dalam praktik produksi pembuatan Almond Crispy Ubi Jalar yang telah dilakukan, formulasi dengan penambahan tepung ubi jalar ungu sebesar 75 gram mampu menghasilkan produk yang lebih maksimal dibandingkan formulasi lainnya. Penambahan tepung ubi jalar ungu sebanyak 75 gram mampu menghasilkan warna yang lebih baik (tidak pudar), aroma atau citarasa yang konsisten atau baik, rasa yang tidak terlalu manis dan tekstur yang tidak mudah patah atau rapuh. Pemilihan formulasi ini diharapkan dapat menjadi upaya mengurangi ketergantungan terhadap tepung terigu serta mampu menjadi bahan tambahan produk yang dapat memberikan nilai tambah dalam pemenuhan kebutuhan serat, energi dan nutrisi yang terkandung didalam ubi jalar itu sendiri.

Penetapan formulasi terpilih berdasarkan keseluruhan (overall) tingkat kesukaan panelis terhadap semua parameter. Formulasi terpilih yaitu sampel kode 755 dengan formulasi penambahan tepung ubi jalar kuning sebesar 45 gram. Secara statistika dari sampel kode 311 dan sampel kode 755 tidak berbeda nyata secara signifikan, namun dari perolehan skor angka, maka dipilih sampel 755 (penambahan tepung ubi jalar kuning sebesar 45 gram) yang paling disukai oleh panelis.

Pemilihan formulasi $755(\mathrm{~F} 1=$ $30 \%$ dengan penambahan tepung ubi jalar kuning sebesar 45 gram) dipertimbangkan dari segi kualitas produk yang dihasilkan. Dalam praktik produksi pembuatan Almond Crispy Ubi Jalar yang telah dilakukan, formulasi dengan penambahan tepung ubi jalar kuning sebesar 45 gram sudah mampu menghasilkan produk yang maksimal. Penambahan tepung ubi jalar kuning sebanyak 45 gram sudah memberikan warna yang baik (tidak pudar), aroma atau citarasa yang dihasilkan tidak jauh berbeda dengan formulasi lannya, rasa yang manis serta tekstur yang dihasilkan baik. Sehingga dengan pemilihan formulasi 755 dengan penambahan tepung ubi jalar kuning sebesar 45 gram selain sudah mampu menghasilkan kualitas produk yang baik juga diharapkan dapat mengurangi biaya produksi, sehingga nantinya dinilai dapat meningkatkan laba yang diperoleh. Pemilihan formulasi ini diharapkan dapat menjadi upaya mengurangi ketergantungan terhadap tepung terigu serta mampu menjadi bahan tambahan produk yang dapat memberikan nilai tambah dalam pemenuhan kebutuhan serat, energi dan nutrisi yang terkandung didalam ubi jalar itu sendiri.
1.3 Melakukan Analisis Kimia untuk mengetahui kandungan dalam produk yang diteliti.

\section{Uji Antioksidan}


Pengujian Aktivitas Antioksidan Almond Crispy Ubi Jalar dilakukan menggunakan metode spektrofotometri dengan larutan DPPH. Antioksidan merupakan senyawa yang penting bagi tubuh. Dimana senyawa antioksidan dapat menangkap molekul radikal bebas yang dapat menghambat reaksi oksidatif didalam tubuh yang biasanya mejadi penyebab berbagai penyakit muncul didalam tubuh (Adawiah, 2015).

Dari hasil analisis kimia pengujian aktivitas antioksidan menggunakan DPPH (\%) untuk sampel F3 $=50 \%$ yaitu Almond Crispy Ubi Jalar (Ubi Ungu) sebesar $16,45 \%$. Sedangkan untuk sampel F1 = 30\% yaitu Almond Crispy Ubi Jalar (Ubi Kuning) diperoleh hasil pengujian aktivitas antioksidan menggunakan DPPH (\%) sebesar $11,83 \%$. Hasil kadar antioksidan yang berbeda dari tiap sampel dipengaruhi dari jumlah banyaknya formulasi yang digunakan saat produksi. Selain itu hal ini dipengaruhi dari karakteristik masing masing jenis ubi jalar yang digunakan. Dimana pada ubi jalar ungu mengandung antosianin dan ubi jalar kuning mengandung beta-karoten. Selain itu komposisi yang berbeda pada kedua formulasi juga mempengaruhi hasil kandungan Aktivitas Antioksidan yang diperoleh.

\section{Uji Total Kalori}

Pengujian total kalori sampel Almond Crispy Ubi Jalar dilakukan menggunakan alat yang bernama Bom Kalorimeter.

Dari hasil analisis kimia pengujian total kalori pada Tabel 4 dapat diketahui bahwa besarnya kadar total kalori menggunakan Bom Kalorimeter untuk sampel F3 $=50 \%$ yaitu Almond Crispy Ubi Jalar (Ubi Ungu) sebesar $494 \mathrm{kal} / \mathrm{g}$ atau setara dengan $4.940 \mathrm{kkal} / \mathrm{g}$. Sedangkan untuk sampel F1 $=30 \%$ yaitu Almond Crispy Ubi Jalar (Ubi Kuning) diperoleh hasil pengujian total kalori sebesar $519 \mathrm{kal} / \mathrm{g}$ atau setara dengan $5.190 \mathrm{kkal} / \mathrm{g}$.

\subsection{Melakukan Analisis Ekonomi untuk menentukan kelayakan usaha pada produk yang diteliti.}

Perhitungan Analisis Ekonomi ini diperhitungkan berdasarkan rencana 2 outlet yang akan dijalankan pada produksi Almond Crispy Ubi Jalar. Perhitungan 2 outlet ini dimaksudkan untuk meningkatkan produksi serta omset atau pendapatan. Dalam satu kali produksi atau selama 8 jam kerja dengan banyaknya karyawan yaitu 6 orang dibutuhkan bahan baku dan bahan tambahan sebanyak $16,64 \mathrm{~kg}$ untuk menghasilkan produk sebanyak 16,00 $\mathrm{kg}$.

Kapasitas Produksi adalah suatu kemampuan sebuah perusahaan untuk menghasilkan besar/kecilnya produk pada kurun waktu tertentu. Kapasitas produksi untuk 2 outlet dapat dihitung dengan cara : dalam 1 Hari / 1 kali produksi mampu menghasilkan 123 kemasan dimana dalam 1 Kemasan sebanyak 28 keping Almond Crispy Ubi Jalar yang memiliki berat sebesar 130 gram. Maka Kapasitas Produksi/bulan sebanyak 123 kemasan x 25 hari yaitu 3.075 kemasan. 
Biaya Produksi yang dibutuhkan pada produksi Almond Crispy Ubi Jalar sebesar Rp 38.698.640. Diketahui bahwa harga pokok penjualan Almond Crispy Ubi Jalar yaitu sebesar Rp 12.585 dengan harga jual sebesar Rp 14.000 / kemasan 130 gram sehingga diperoleh total penjualan Almond Crispy per bulannya sebesar $\mathrm{Rp} 43.050 .000$ dan diperoleh laba bersih sebesar $\mathrm{Rp}$ 4.047.712

Dalam proses produksi, Almond Crispy Ubi Jalar mencapai titik impas pada tingkat produksi sebanyak 2.187 kemasan (bungkus) dari kapasitas produksi 3.075 kemasan (bungkus) / bulannya. Sehingga selisih dari kapasitas produksi dengan perhitungan BEPunit titik impas yang diperoleh perusahaan adalah keuntungan dari produksi. Penentuan Return on Investment (ROI) dalam produksi Almond Crispy Ubi Jalar sebelum pajak adalah sebesar 8,2\% dan ROI dalam produksi Almond Crispy Ubi Jalar setelah pajak adalah sebesar 9,8\%.

Kembalinya modal atau keuntungan bersih dalam perhitungan Pay Out Time (POT) diperoleh setelah proses produksi berlangsung selama 29 bulan (2 tahun, 5 bulan) serta NPV sebesar $525,860,607$ pada MARR 9\%. Sehingga NPV $>1$ yang berarti usaha produksi Almond Crispy Ubi Jalar dapat atau layak untuk dijalankan dengan keuntungan sebesar nilai NPV dalam kurun waktu 5 tahun. Pada analisa Benefit Cost Ratio (Net B/C) produksi Almond Crispy Ubi Jalar diperoleh besar B/C rasio sebesar 4,0 atau rasio yang diperoleh $>1$, artinya usaha ini layak untuk dijalankan dan IRR sebesar 147,97\% > DF 1 (80\%), yang artinya usaha untung dan layak dijalankan.

\section{KESIMPULAN}

Dalam proses pembuatan Almond Crispy Ubi Jalar dilakukan dengan beberapa tahapan proses meliputi Pencampuran (Mixing), Penambahan dan Pencampuran Bahan Kering, Pembentukan Adonan, Pemanggangan (Pengovenan), Pendinginan dan Pengemasan. Sampel Almond Crispy Ubi Jalar (Ubi Ungu) yang paling disukai adalah sampel dengan kode 313 yaitu sampel dengan penambahan tepung ubi jalar sebanyak 50\% (75 gram dari 150 gram tepung terigu). Sampel Almond Crispy Ubi Jalar (Ubi Kuning) yang paling disukai adalah sampel dengan kode 755 yaitu sampel dengan penambahan tepung ubi jalar sebanyak 30\% (45 gram dari 150 gram tepung terigu).

Kadar Aktivitas Antioksidan pada sampel Almond Crispy Ubi Jalar untuk Ubi Ungu sebesar 16,45 \% dan Ubi Kuning sebesar 11,83 \%. Kadar Total Kalori pada sampel Almond Crispy Ubi Jalar Ubi Ungu sebesar $494 \mathrm{kkal} / \mathrm{g}$ dan Ubi Kuning sebesar 519 kkal/g. Kapasitas produksi Almond Crispy Ubi Jalar sebanyak 3.075 kemasan per bulan, dengan harga pokok produksi sebesar $\mathrm{Rp}$ 12.585/kemasan, harga jual sebesar Rp 14.000/kemasan, sehingga diperoleh laba bersih sebesar Rp 4.047.712/bulan. Usaha mencapai titik impas pada produksi sebanyak 1.093 kemasan / bulan. NPV yang diperoleh sebesar 525,860,607 pada 
MARR 9\% dimana NPV > 1 yang berarti usaha produksi Almond Crispy Ubi Jalar dapat atau layak untuk dijalankan dengan keuntungan sebesar nilai NPV dalam kurun waktu 5 tahun. Net B/C produksi Almond Crispy Ubi Jalar diperoleh besar B/C rasio sebesar 4,0 atau rasio yang diperoleh $>1$, artinya usaha ini layak untuk dijalankan. IRR yang diperoleh sebesar $147,97 \%$ > DF 1 (80\%), maka usaha untung dan layak dijalankan.

\section{DAFTAR PUSTAKA}

Adawiah, Dede Sukandar, Anna Muawanah. 2015. Aktivitas Antioksidan dan Kandungan Komponen Bioaktif Sari Buah Namnam. Jurnal Kimia VALENSI: Jurnal Penelitian dan Pengembangan Ilmu Kimia. 1 (2).

Anonim. 2017. Proses Pembuatan Almond Crispy (Toko Wahab).

Https://www.tokowahab.co $\mathrm{m} /$ resep/resep-membuatalmond-crispy-cheese/. Diakses pada 2 Januari 2018.

Astawan M. 2004. Tetap Sehat Sengan Produk Makanan Olahan. PT Tiga Serangkai: Surakarta.

Khotimah H, Sutiono. 2014. Analisis

Kelayakan Finansial Usaha Budidaya Bambu. Jurnal Ilmu Kehutanan, 8 (1).

Tarwendah., Ivani Putri. 2017. Studi Komparasi Atribut Sensoris Dan Kesadaran Merek Produk Pangan. Jurnal Pangan dan Agroindustri, 5 (2). 